\title{
E-Assessment System Based on IMS QTI for the Arabic Grammar
}

\author{
Abdelkarim Abdelkader \\ Computer Science Department \\ College of Computer at Al-Gunfudah \\ Umm Al-Qura University \\ Al-Gunfudah, Saudi Arabia
}

\author{
Dalila Souilem Boumiza \\ Prince Research Group, ISITCom, \\ University of Sousse, \\ Tunisia
}

\author{
Rafik Braham \\ Prince Research Group, ISITCom, \\ University of Sousse, Tunisia
}

\begin{abstract}
Nowadays e-learning has become a fundamental stream of learning. E-assessment is an important and essential phase of the e-learning process because of all the decisions we will make about learners when teaching them. In this paper, we describe an e-assessment system for the Arabic grammar. Our system is based, on the one hand, on linguistics tools and on the other hand, it integrates the Question and Test Interoperability (QTI) proposed by IMS Global Learning Consortium. We adopt the IMS-QTI specification to build an interoperable, reusable and sharable e-assessment system. This system is composed of three main components. The first component is a set of linguistic tools and resources. The second represent an authoring tool which allows teachers to create questions and tests accordance with the IMS-QTI specification. The third component is an Arabic test player for parsing and interpreting QTI XML files.
\end{abstract}

Keywords-Arabic Grammar; E-assessment; IMS QTI; ANLP QTI-Based Tools

\section{INTRODUCTION}

The Internet and the advanced technologies show its advantages in our everyday activities especially in the learning way. So, electronic learning or web-based learning or, quite simply, e-learning has becoming an essential stream of education in present and has a promising future. It has a great attention as an important research area and it has evolved considerably.

The life-cycle of the e-learning process from the planning and preparation of a course to its use by the students comprises of four main phases: the design phase, the production phase, the deployment phase and the assessment phase [1].

The learning design phase includes the required features of students' profile, the competencies definition and the targets' specification. In the production phase, the content is produced, assembled and packaged to be delivered. The deployment phase focus on the ability of learners to access and use the content and collaborate during the e-learning operation. The process ends with the assessment phase. The purpose of this important phase is twofold. It concerns the whole process and the gains of students through questions, tests, exams and other activities [1].

In this paper we are concerned with the last phase: Eassessment phase. In fact, the assessment in traditional education or in online education is an important and powerful phase. It is the process of examining a subject and rating it. The goal is to determine how much or how little we value something, arriving at our judgment on the basis of criteria that we can define. It comes in three varieties: formative (provide feedback during the learning process), summative ( at the end of the process) and diagnostic.

The design and the development of e-learning resources or e-lessons or e-assessment content is an expensive task and time consuming and these tasks need high collaboration. Wherefore different collaborative partners bring with them different technologies and in order to maximize return on investment and ensure e-learning content that is truly interoperable and not tied to one particular learning management system such as caroline or Moodle, content must be described and accessed according to standards. Therefore, the creation of technical specifications and the development and widespread adoption of technical standards will be fundamental to the success of elearning [2].

In this work, we try to propose the design and the implementation of an e-assessment system for the Arabic grammar which ensures teaching and provide a interoperable testing content that can be reused and shared between different compliant systems. This system is based on the one hand, on linguistics tools like morphological and syntax analyzer, and on the other hand on IMS Question and Test Interoperability specification (QTI). We adopt the specification of IMS QTI to create a standardized e-assessment system.

The organization of this paper is as follows: the first section introduced the motivation and the overview of this paper. The second section shows the importance of assessment in the learning field and its varieties. The third section provides background information on e-learning standards. We focus on the standard of evaluation: IMS QTI. The fourth section introduces the architecture and the detailed design of the experimental e-assessment system for the Arabic grammar and covers the implementation of this system and its different components. In the fifth section, we will give a summary of the Arabic grammar and we will describe a set of linguistic tools (a lexicon, a categorization algorithm and a parser) that we have developed and integrated to build our e-assessment system. The sixth section covers the implementation of two QTI based tools. First, we present an authoring tool which allows teachers to create questions and tests accordance with the IMS-QTI and we discuss the types of exercises that we can do to learn the grammar of the Arabic language and we show how to specify 
them using the IMS QTI standards. After that, an Arabic test player for parsing and interpreting QTI XML files will be presented. The last section summarizes the work, and discusses the research contribution and the future works related to the e-learning environment for the Arabic language.

\section{IMPORTANCE AND VARIETIES OF E-ASSESSMENT}

In the traditional learning or in the online learning assessment is a fundamental part of the learning process because it is, on the one hand, a means of providing prompt and effective feedback and, on the other hand, a tool to encourage active learning. Assessment is required in order to:

- determine the parts of lesson that has not been well understood, therefore helping to inform evaluation of teaching methods and approaches.

- decide performance, measured against intended learning results.

- Identify whether progression to the next level is appropriate.

- Prepare necessary feedback, which indicates the learner level and the areas for improvement.

The assessment can be considered as the collection, synthesis and interpretation of information to help the teachers in decision making done before, during and after teaching.

a) Before teaching: Assessment is needed to aid teachers make decisions about learning goals, learning activities and appropriate materials.

b) During teaching: Assessment is needed to help teachers make decisions about the delivery and pace of instruction, control behavior, keep students attention, and adjust the scope and sequence of learning activities.

c) After teaching: Assessment is needed to help teachers evaluate student learning, as well as learning materials. Assessment at this stage helps teachers to know what to teach next and helps to improve instruction. Assessment at the end of an teaching unit provides information for grading students and evaluating teaching.

E-assessment or assessment in general comes in three varieties: diagnostic, formative and summative.

Diagnostic assessments (also known as pre-assessments) provide instructors with information about student's prior knowledge and misconceptions before beginning a learning activity. They also provide a baseline for understanding how much learning has taken place after the learning activity is completed. Teachers usually build concepts sequentially throughout a course.

Formative Assessment: take place during a learning activity to provide feedback and information during the instructional process, while learning is taking place, and while learning is occurring. Formative assessment measures student progress but it can also assess the own progress of the instructor. In the elearning field, this assessment plays an important role to get distance students motivated because they feel a sense of not being lost in space.
Summative Assessment: Summative assessment takes place after the learning has been completed and provides information and feedback that sums up the teaching and learning process. Typically, no more formal learning is taking place at this stage, other than incidental learning which might take place through the completion of projects and assignments.

Summative assessment is more product-oriented and assesses the final product, whereas formative assessment focuses on the process toward completing the product.

Compared to the traditional learning environment, new technology has made frequent and varied assessments possible in the online distance education environment [3]. However, the most important thing for assessment in the new online learning environment is to still focus on learners' achievement in terms of instructional goals and objectives. Therefore, even though technology can facilitate the process of assessment in effective and efficient ways, the authors must choose appropriate assessment opportunities only when assessments are essential during teaching.

Over the last few decades, many researchers have been convinced that assessment of learner achievement in online distance environments should be integral to instruction, be continuous, and maximize feedback [3]. Now, e-assessment is one of the distance learning research issues; it plays a very important role in this field. In order to make questions and test items more accessible and interoperable, the standardized eassessments contents are promoted. The following section provides background information on e-learning standards. We focus on the standard of evaluation: IMS QTI.

\section{E-LEARNING STANDARDS}

Despite the wide spread use of e-Learning infrastructure in corporate and educational environments, current approaches to the development of e-Learning content are expensive and time consuming. It is common that content developed by a single vendor or educational institution can be difficult to reuse by a second vendor or institution, even though the content shares the same meaning and quality [4]. Failure of systems to interoperate or exchange content and differences in content ontology between institutions make content reusability and sharing difficult, although content sharing and reusability will reasonably reduce production cost.

In order to make e-Learning content less expensive to produce and portable across different hardware and software systems, a new way of developing e-learning content has been proposed. This new approach assumes that e-Learning content can be organized and disseminated in a uniform format as small chunks of learning materials commonly referred to as learning objects or knowledge objects [5] and [6]. It seems that developing and delivering learning content as objects will promote reusability, interoperability and content sharing between different training vendors and educational institutions. When combined, the learning objects, due to their reusability in different learning scenarios may form educational resources that can be used in different environments by different individuals. This realization leads many course developers to believe that the learning object can become the foundation of adaptive instructional systems that deliver individually tailored 
learning materials to large number of people at the same time [7]. With standards it is possible for learning materials to be reused and to travel on different systems.

Many organizations are concerned with e-Learning specifications that the learning community may support. Amongst them, Learning Technology Standards Committee (LTSC) from Institute of Electrical and Electronic Engineers (IEEE), the Aviation Industry Computer-Based Committee (AICC), the Instructional Management System (IMS), the Advanced Distributed Learning (ADL) and the Educational Modeling Language (EML) are the leading ones [7] and [8].

IMS may be the most influential organization in the eLearning community. The contributing members of IMS include many well-known academic, corporate, non-profit and government organizations. IMS is developing and promoting open specifications for facilitating online distributed learning activities such as locating and using educational content, tracking learner progress, reporting learner performance, and exchanging student records between administrative systems [9].

Because XML has shown its advantage in the interoperability and reusability of data, IMS adopts XML in all of its specifications. Now five specifications are available. When designing our e-Learning system, we were aware of these specifications and tried to adopt them in our system [10]:

- The IMS Learning Resources Meta-data Specifications creates a uniform way for describing learning resources so that they can be more easily found [11].

- The IMS Enterprise Specification deals with administrative applications and services that need to share data about learners, courses, performance, etc., across platforms, operating systems, user interfaces.

- The IMS Content \& Packaging Specification is concerned with creating reusable content objects [12].

- The IMS Question \& Test Specification addresses the need to be able to share test items and other assessment tools across different systems [13].

- The IMS Learner Profiles Specification looks at ways to organize learner information so that learning systems can be more responsive to the specific needs of each user [14].

The adoption of standards and specifications facilitates the dominance of platform independent, open technologies and promotes user-centric e-learning systems. Standardized technologies have several merits that protect and nurture an elearning investment [15] and [16]. These are in general:

- Interoperability: is the ability of a system to work with or use the parts or equipment of another system.

- Accessibility: A learner can access the appropriate content at the appropriate time on the appropriate device. Content warehouses can be developed and become available to amateurs or professionals that use any application based on the common standards.

- Durability: Content is produced once and transplanted many times in different platforms and systems with minimum effort.

- Re-usability: Content and code can be assembled, disassembled, and re-used quickly and easily.

- Scalability: Learning technologies can be expanded in functionality in order to serve broader populations and organizational purposes.

The IMS Question and Test Interoperability Specification provide proposed standard XML language for describing questions and tests. The specification has been produced to allow the interoperability of content within assessment systems [13]. It describes a basic structure for the representation of question (item) and test (assessment) data and their corresponding results reports. Therefore, the specification enables the exchange of this test, assessment and results data between Learning Management Systems, as well as content authors and, content libraries and collections.

IMS Question and Test Interoperability (QTI) [17] and [18] is an international specification for a standard way of sharing testing and assessment data. This specification is now being implemented within a number of assessment systems and Virtual Learning Environments. Some systems store the data in their own formats but support the export and import of question data in IMS QTI format. Other systems operate directly on IMS QTI format data.

The QTI specification uses XML to record the information about assessments. XML is a powerful and flexible markup language that uses 'tags' rather like HTML. The IMS QTI specification supports different types of user responses (item selection, text input, numeric input, xy-position selection and group selection) that can be combined with several different input techniques (radio button, check box, text entry box, mouse xy position dragging or clicking, slider bar and others)[19].

\section{ARCHITECTURE OF E-ASSESSMENT SYSTEM}

The complete architecture of the e-assessment system for the Arabic grammar is presented in Fig.1. This system supposes a web-based infrastructure as a basis for its technical implementation. Thus, learners interact with the e-learning system through browsers in the client side, and get the learning contents in HTML format [19].

The proposed e-assessment system is composed of three main components. The first component is a set of linguistic tools and resources. The second represents an authoring tool which allows teachers to create questions and tests accordance with the IMS-QTI specification. The third component is an Arabic test player for parsing and interpreting QTI XML files. On the following sections, we describe deeply these three components. 


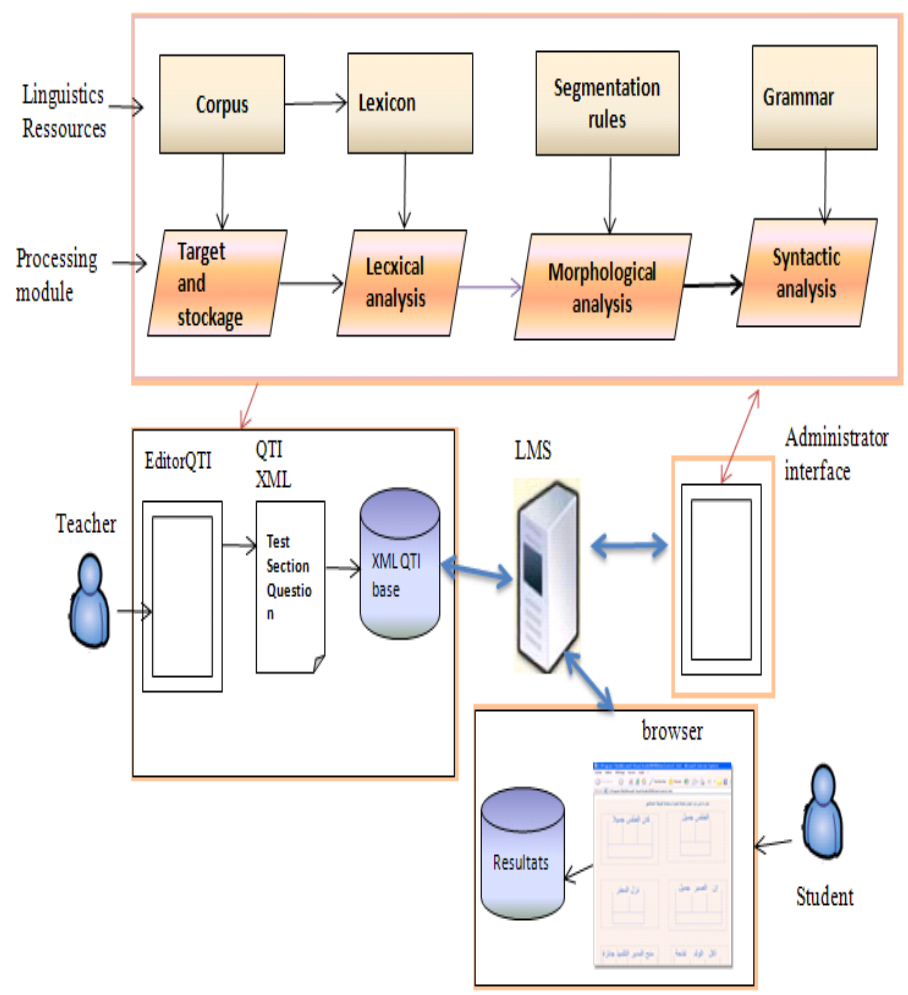

Fig. 1. The proposed e-assessment system architecture

\section{DEVElOPPED Linguistic TOOLS}

As we mentioned in the first section of this paper, we developed a new tools and algorithms, and also using the existing ones such as AlKhalil [20] to serve the e-learning of the Arabic grammar. Before talking about this tools and resources, it is necessary to conduct a linguistic study concerning the Arabic grammar. This study is based on discussions with linguistic experts to understand the Arabic grammar and linguistic phenomena like the coordination, the anaphor, the ellipse, etc. The objective is to be able to recognize almost all of grammatical constructions in any Arabic simple sentence. So, we begin this section by studying the typology of the nominal and verbal sentence specifying its different forms.

1) overview of the Arabic grammar

Arabic generally follows a verb/subject/object construction, but a conjugated verb can form a sentence of its own. For example, "aktobo" means "I write." Arabic also has more complex sentence structures, but the two main types are nominal and verbal. Nominal sentences are formed when the head is a noun or when the subject precedes the verb. This structure is used when the subject is the focus of sentence. When the subject follows the verb, this is called a verbal sentence. This is the normal form of a sentence in Arabic and does not occur in English. Fig.2. shows the types and the constituents of the simple Arabic sentence.

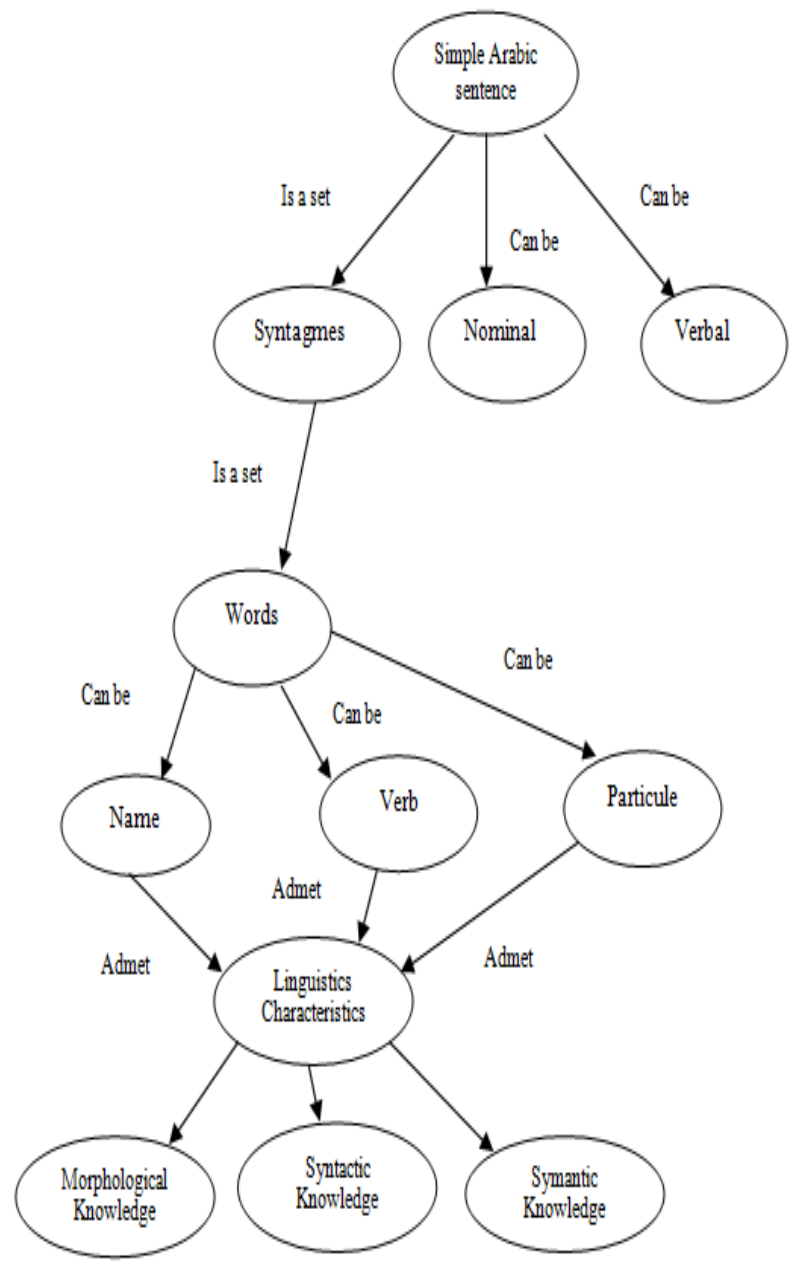

Fig. 2. The constituents of the simple Arabic sentence

Fig.3. shows the different forms of the simple Arabic sentence. 


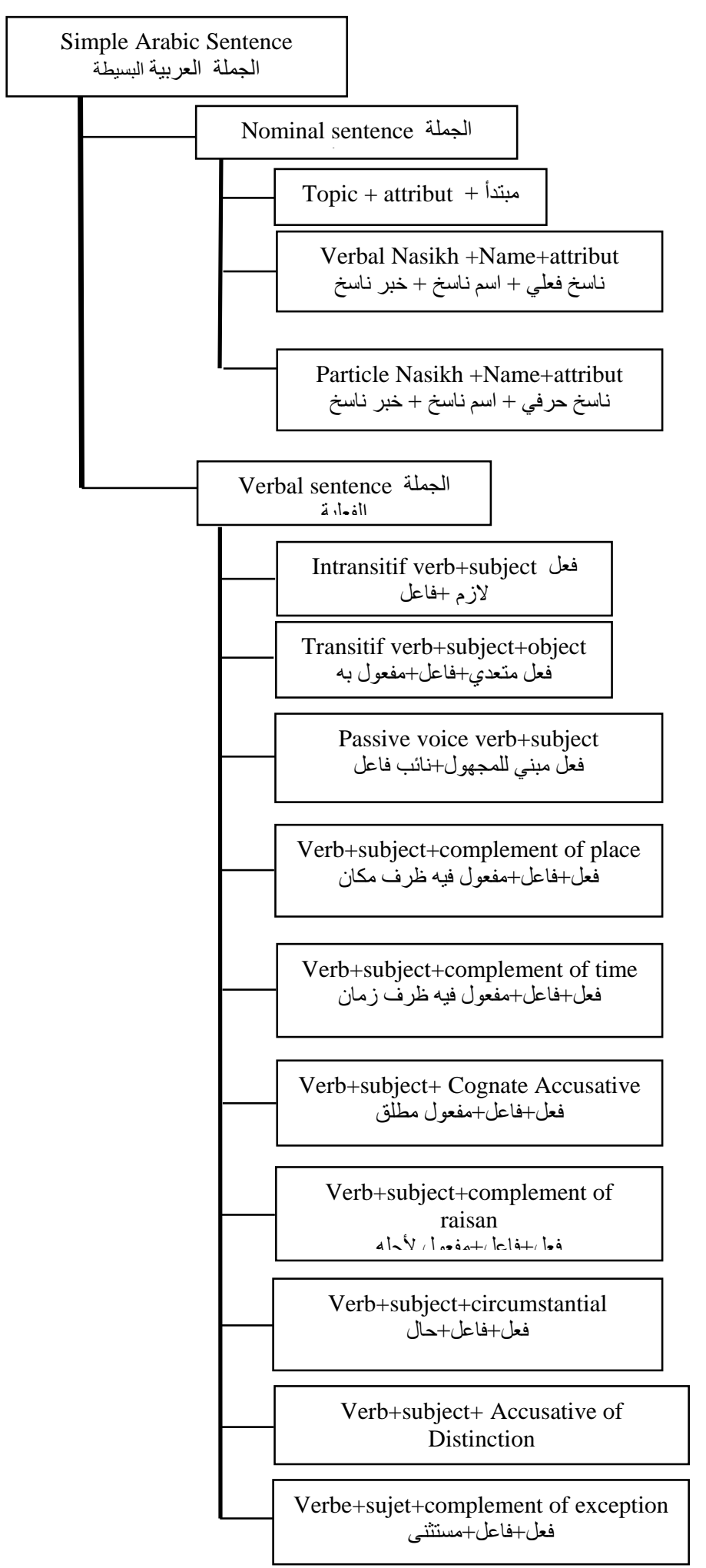

Fig. 3. Typology of the simple arabic sentence

The following figure represents the different forms of the topic in the nominal simple sentence.

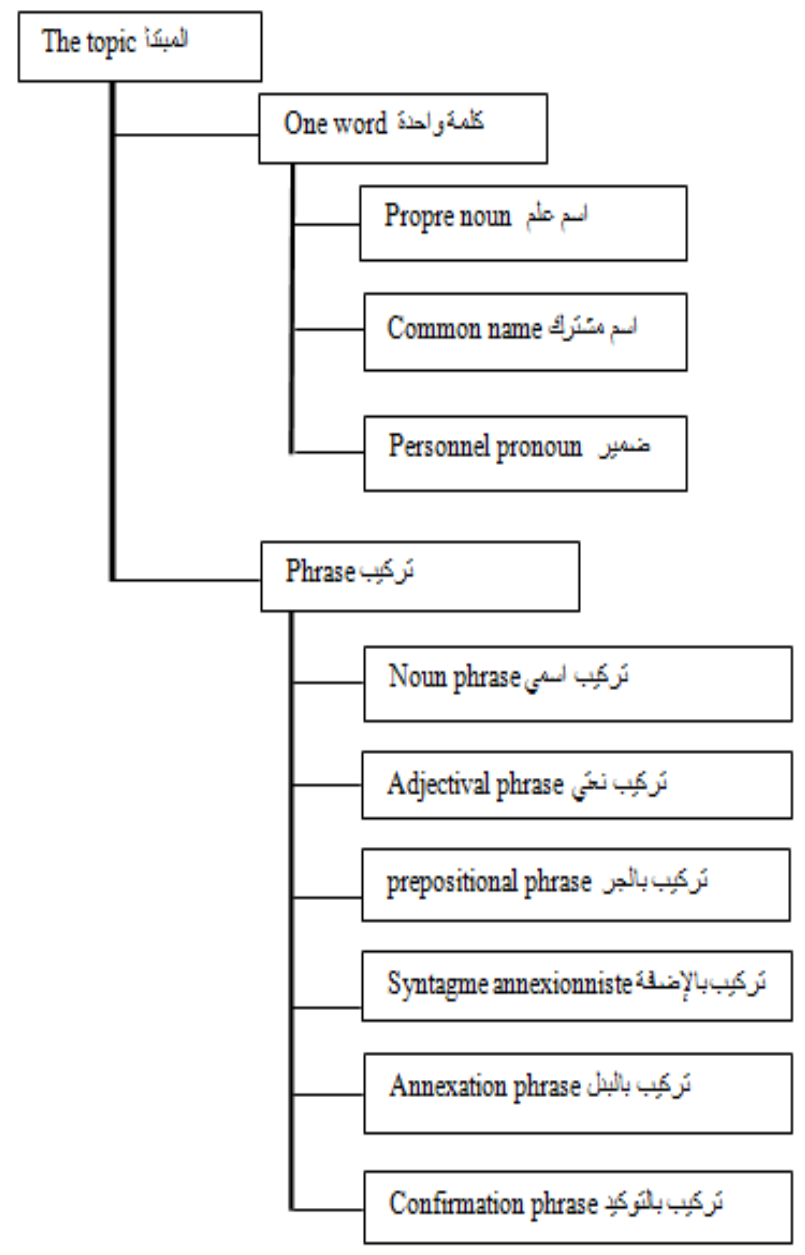

Fig. 4. Typology of the topic in the nominal simple sentence

\section{2) The selected corpus}

We have selected a small corpus of representative texts from Arabic grammar books through literary texts for the pupils of seventh year of the Tunisian basis teaching [21]. This corpus contains short texts constituted by nominal and verbal simple sentences:

- The simple sentence and its characteristics الجملة البسيطة وخصائصها التركبيية

- The essential forms of the simple verbal sentence الأشكال الأساسية للجملة الفعلية البسيطة

- The transitive verb and the intransitive verb

- The verb in the passive voice

$$
\text { الفعل اللازمو الفعل الدتعدي }
$$

$$
\text { الفعل الدبنى للمجهول }
$$

- The essential forms of the simple nominal sentence

- The topic and attribute

$$
\text { الأشكال الأساسية للجملة الإِسمية }
$$

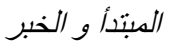

- The nominal sentence starting with a verbal nasikh

$$
\text { الجملة الاسمية الدسبوقة بناسخ فعلي }
$$

- The nominal sentence starting with a verbal nasikh

$$
\text { الجملة الاسمية المسبوقة بناسخ حرفي }
$$


- The simple sentence and complements

$$
\text { إغناء الجملة البسبطة بالكتمعات }
$$

This corpus contains ten texts by subject. Every text contains approximately twenty sentences. Every sentence consists from two to seven words.

\section{3) Morphological analyzer}

Morphological analysis is the first step in natural language processing. The objective of this step is to identify words in a sentence. Methods and strategies for morphological analysis differ by types of language. For the Arabic language, since Arabic morphological analysis techniques have become a popular area of research, several systems are known in the Morphological Analysis domain [22], for example, the Khoja stemmer [22], the Buckwalter Morphological Analyzer [23], AMIA Morphological Analyzer [24] and AlKhalil Morpho System [20]. AlKhalil (AlKhalil Morpho Sys) could be considered as the best Arabic morphological system, it won the first position, among 13 Arabic morphological systems around the world, at a competition held by the Arab League Educational, Cultural and Scientific Organization (ALECSO) ( (المنظمة العربية للتربية و الثقافة و العلوم and King Abdul Aziz City for Science and Technology (KACST). So, we had put a special effort on understanding and testing it and used its open source database as part of our linguistics resources. For a given word, AlKhalil identifies all possible solutions with their morphosyntactic features: vowelizations proclitics and enclitics, nature of the word voweled patterns, stems and roots[20].

\section{4) Categorization algorithm}

In the Arabic language, the non voweled words are grammatically ambiguous. To minimize the ambiguity, we presented in [25] a method of disambiguation having for goal to find all categories of the words in an Arabic text. This method is based on linguistic knowledge. For example, if the word that immediately precedes the homograph is a personal pronoun or a proper name, then this homograph is a conjugated verb. But if the word that immediately precedes the homograph is a determinant, then this homograph is a name.

\section{5) Syntactic analysis}

Syntactic analysis is the most important step in natural language processing. It is concerned with the construction of sentences. It indicates how the words are related to each other.

For the simple Arabic sentence, we proposed a HPSGbased analysis system. This system requires three phases: the segmentation and the categorization of the words constituting the sentence to analyze, the loading of the AVM (Attribute Value Matrix) of the words of the sentence, and the actual syntactical analysis. The first phase consists in segmenting the sentence into words using the spaces like indicators of separation. In Arabic, there are other difficulties of segmenting that are due either to the agglutination, or to the derivation. To solve these problems, we used the AlKhalil Morpho System. The second phase permits to take in charge all information concerning every word composing the sentence under shape of AVM. The phase of syntactic analysis uses the "Chart Parsing HPSG" algorithm [26]. Fig.5. shows our proposed syntactic analysis method.

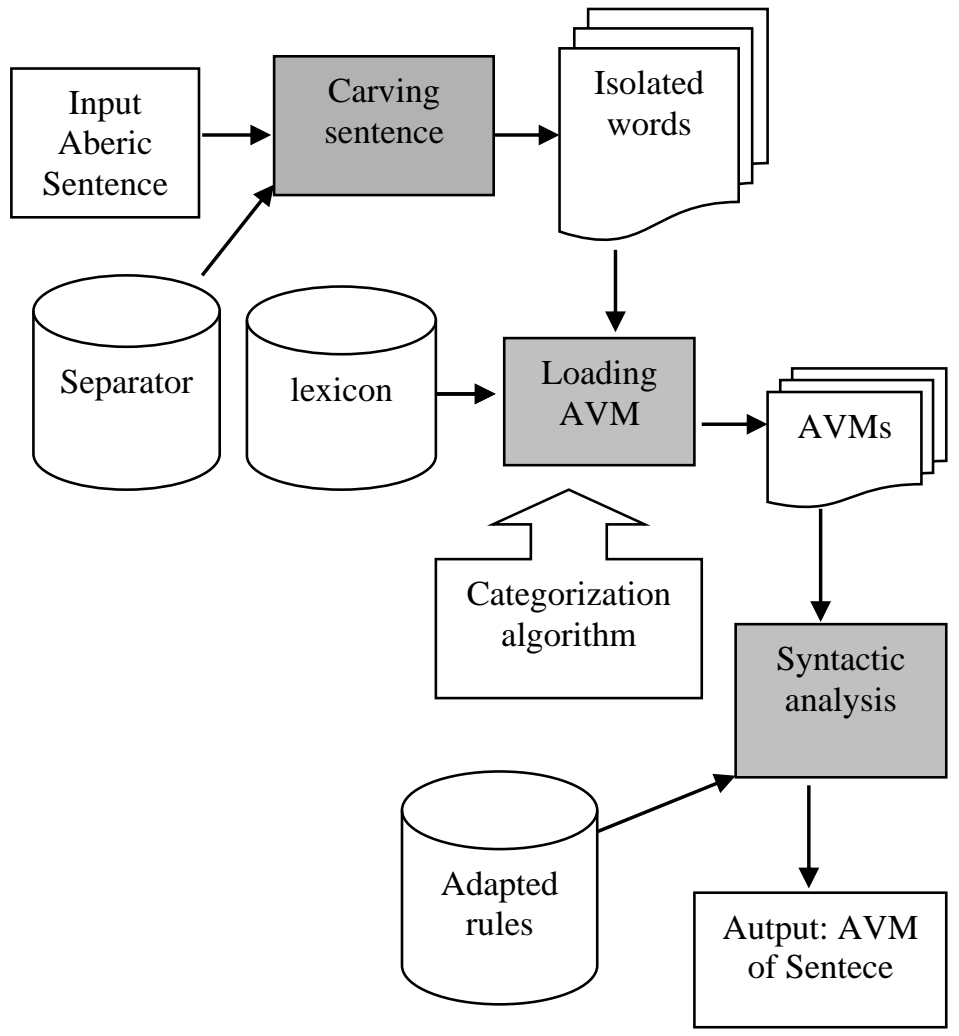

Fig. 5. The Proposed syntactic analysis method.

All this linguistic tools are used to create and specify with IMS QTI specification some grammar exercises such as the categorization exercise "صندقة". This type of Arabic grammar exercises consists of determining the grammatical function of each word of the sentence. An example is shown in Fig.6.

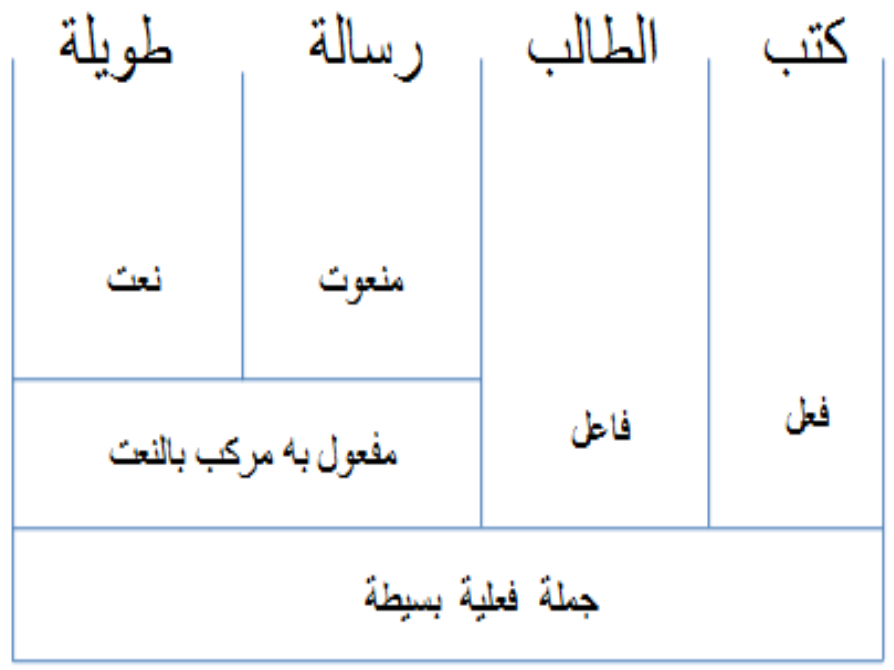

Fig. 6. Example of a categorization exercise

\section{ARABIC IMS-QTI EDITOR}

In this section, we present an authoring tool which allows teachers to create sharable and reusable questions and tests 
accordance with the IMS-QTI specification and accessible across different learning management systems (LMS) like moodle or WebCT. The teacher can create several types of questions :

1) Questions with a single answer (exclusive choice): The teacher may enter the question, the question description, a several possible answers (الاجابات) and it may choose one correct answer (إجابة صحيحة واحدة). If he selectes another button (radio button), the first radio button is unselected and switches to the new answer.

2) Multiple choice questions (MCQ): This type of question allows teacher define one or more answers. It is similar to the previous one. However, the "radio buttons" have been replaced by boxes to tick, and the learner can choose several answers.

3) Alphanumerical input field (text field): The answer is provided by inputting a word or numbers in the proposed input field.

4) True or false question: The teacher may only choose the correct answer (True or False).

5) Drag and drop: The answers to this type of question are words or sentences that the teacher must fixe their correct order. Next, the student must move to the corresponding targets.

6) Categorization: The answers to this type of question are a tree that represents the grammatical function of each word of the sentence.

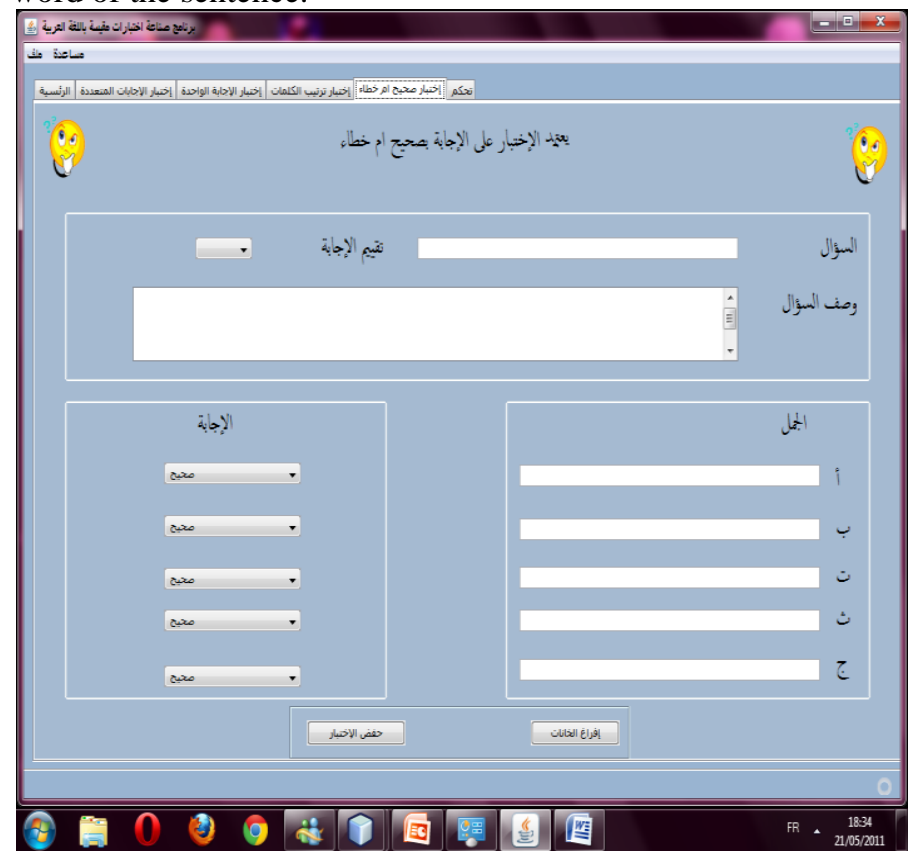

Fig. 7. True or false question

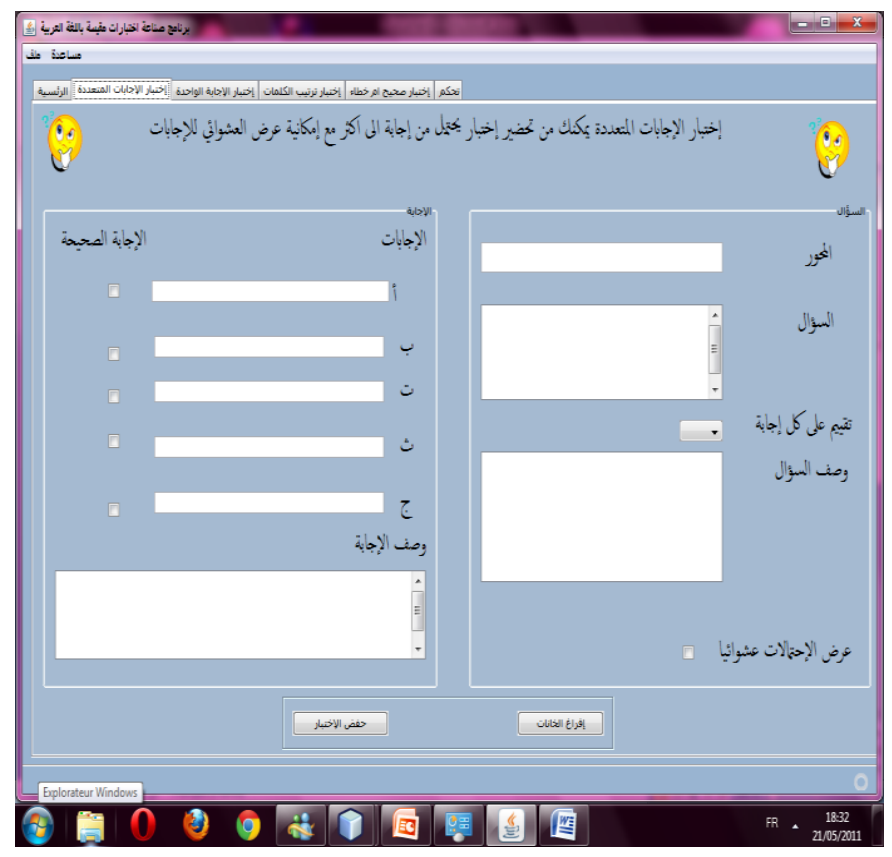

Fig. 8. Multiple choice question

Fig.7. and Fig.8. represent tow graphical interfaces for the true or false question and the multiple choice question.

The main task of this tool is to create interoperable, sharable and reusable question files. The exported files will be in XML formats which conform to the QTI 2.1 specification and stored in the content package. The content package contains three sorts of XML files:

- the manifest file: a QTI XML file which describes the metadata, question items, and material files. This file named Qmanifest.xml.

- the material files: set of files required by the question item like image files.

- the question items : a QTI XML files with .xml extension and describe question details.

\section{B. Arabic grammar player}

Arabic grammar player is a reader that interprets and displays IMS/QTI documents (XML). The learners doesn't have to worry about graphics, navigation between questions or even score calculation. The player supports all types of questions created by the teacher using our authoring tool: True or False question, drag and drop, categorization... The categorization question type requires all the linguistic tools described in section 5 to automatically verify and correct the learner's answers.

Fig.9. shows the graphical interpretation of a multiple choice question and Fig.10 shows the result of multiple choice questions. 


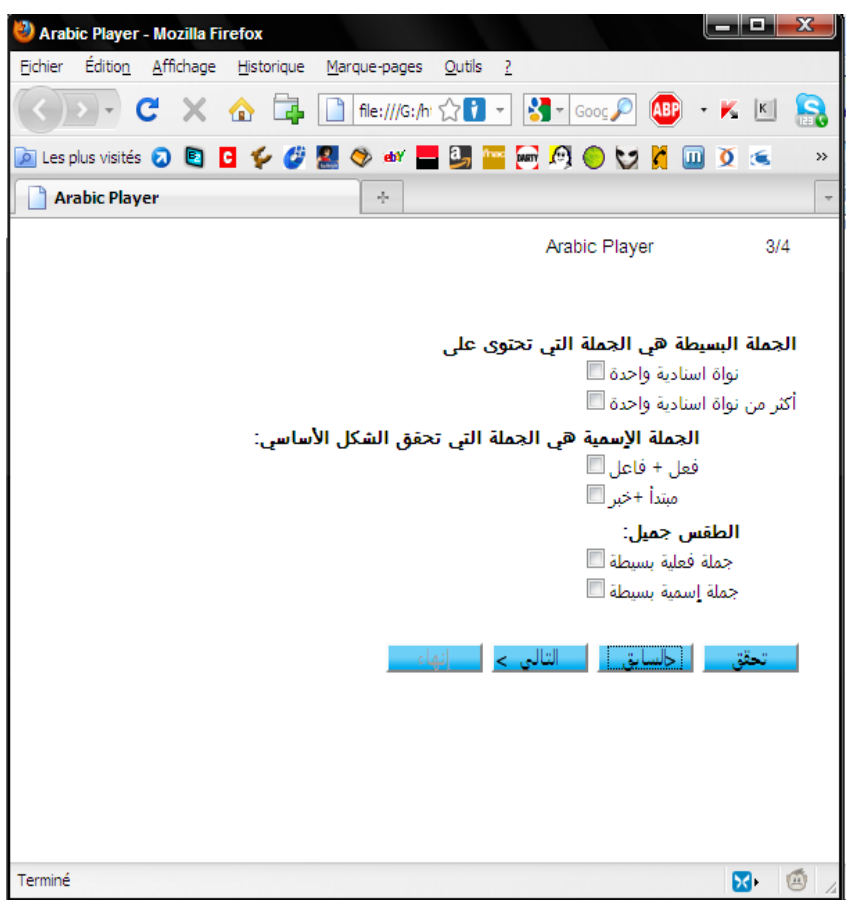

Fig. 9. Interpretation of multiple choice question

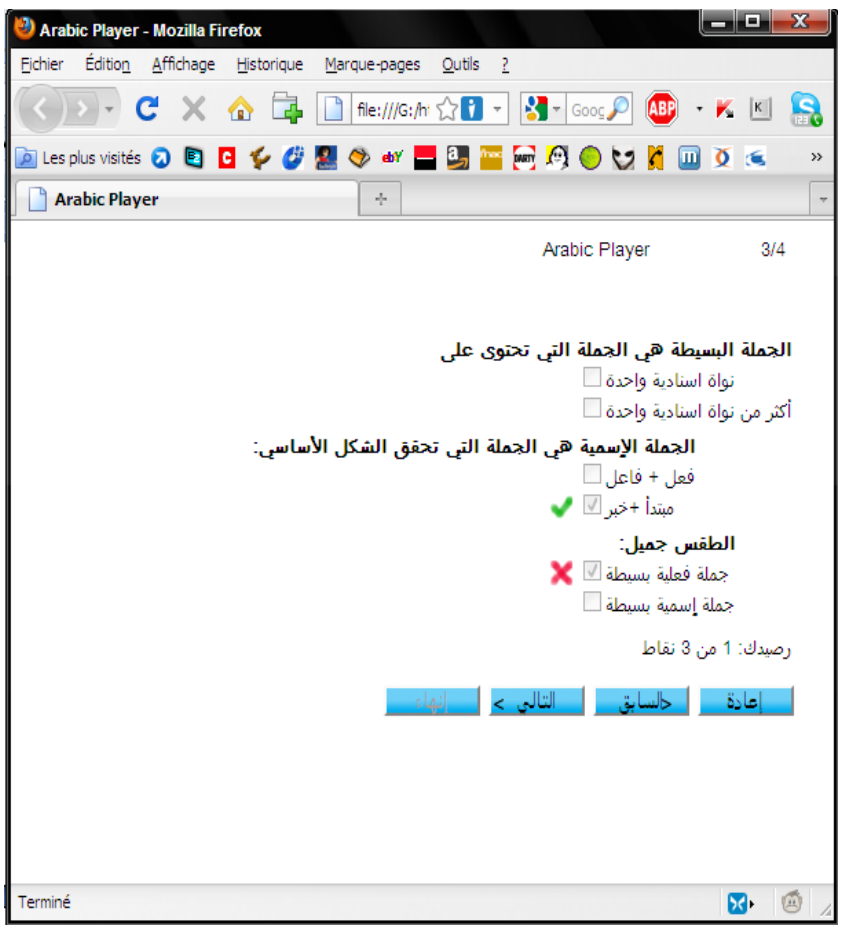

Fig. 10. Result of multiple choice question

\section{CONCLUSION}

In this paper, we presented our research work concerning the design and the implementation of an e-assessment system for the Arabic grammar based on linguistic tools and IMS QTI specification. We adopt this specification to ensure the interoperability between systems, the re-usability, the durability and the accessibility of contents, tests and questions. NLP technology, resources and tools are used to help teachers in preparation of better reading comprehension tests in shorter time and can be used to automatically verify and correct the learner's answers. All the components of the system are integrated in the moodle platform.

As future work, we intend to continue the development of module that permit to automatically generate questions and tests accordance with the IMS-QTI specification.

\section{REFERENCES}

[1] A. Abdelkader, D. Souilem Boumiza, and R. Braham, "A linguistic tools and e-learning standards to build an assessment system for the Arabic language," 5th International Symposium on Distance Education, Tunisia, July 2009.

[2] I. Varlamis, L. Apostolakis, and A. Koohang, "The present and future of standars for e-learning technologies," Interdisciplinary journal of knowledge and learning objects. Vol. 2, pp.59-76, 2006.

[3] E.L. Meyen, R. J. Aust, Y. N. Bui, and R. Isaacson, "Assessing and monitoring student progress in an e-learning personnel preparation environment," Teacher education and special education, 25 (2). 187198, 2002.

[4] S. Downs, Learning 2000 http://www.atl.ualberta.ca/downes/naweb/column000523.html.

[5] J. Clayton, Content Reuse for XML Based Courseware. XML 2000, Washington, DC, December 3, 2000.

[6] R. Feemster, The Future of Online Learning lies in Course Objects. University Business; 2000. http://www.universitybusiness.com/0007/merlot.html (Accessed on July $5,2014)$

[7] H. Wu., "Designing a Reusable and Adaptive E-Learning System," Degree of Master of Science in the Department of Computer Science University of Saskatchewan. Saskatoon, November 2002.

[8] D.H. Leo, J.I. Asensio, and Y. A. Dimitriadis, "IMS Learning Design Support for the Formalization of Collaborative Learning Patterns," 4th International Conference on Advanced Learning Technologies (Best Paper Award), ICALT'04, , Joensuu,Finland ,350-354, 2004. http://ulises.tel.uva.es/uploaded_files/leoicalt2004.pdf

[9] M. Robles, and S. Braathen, "Online assessment techniques," Delta Pi Epsilon Journal, 44 (1). 39-49, 2002.

[10] Instructional Management System (IMS), http://www.imsproject.org/ (Accessed on September. 20, 2014)

(2014).

11] Instructional Management System (IMS). (2014). IMS Content Packaging Best Practices and Implementation Guide.http://www.imsproject.org/content/packaging/index.html (Accessed September. 20, 2014)

[12] Instructional Management System (IMS). (2014). IMS Learner information Best Practices and Implementation Guide. http://www.imsproject.org/profiles/index.html (Accessed on September. 20, 2014)

[13] Instructional Management System (IMS). (2014). IMS Learning Resource Meta-data Best Practices and Implementation Guide. http://www.imsproject.org/metadata/index.html (Accessed September. 20, 2014)

[14] Instructional Management System (IMS). (2014). IMS Question and Test Best Practices and Implementation Guide. http://www.imsproject.org/question/index.html(Accessed on September. 20, 2014)

[15] C. Fallon, and S. Brown, E-learning standards: A guide to purchasing, developing and deploying standards-conformant e-learning. St. Lucie Press, 2002.

[16] N. Friesen, "Interoperability and learning objects: An overview of elearning standardization," Inter-disciplinary Journal of Knowledge and Learning Objects, pp. 23-31, 2005.

[17] P. H. Amalric, La spécification IMS Simple Sequencing, 14-16 rue Molière, 92400 Courbevoie - La Défense, 2007.

[18] O. Auzende, "Propositions d'extensions à IMS-QTI 2.1 pour l'expression de contraintes sur les variables d'exercices mathématiques 
Extensions à QTI 2.1 pour l'expression de contrainte," Manuscrit auteur, publié dans (2007).

[19] A. Abdelkader, D. S. Boumiza, and R. Braham, "An Online Arabic Learning Environment Based on IMS-QTI," The 10 Th IEEE International Conference on Advanced Learning Technologies, Sousse Tunisia, July 5-7, 2010.

[20] Alkhalil Morpho Sys: A Morphosyntactic analysis system for Arabic texts (2010, April 16). Retrieved February, 2014, from ALECSO: http://www.alecso.org.tn/index.php?option=com_content\&task=view\&i $\mathrm{d}=13$ 02\&Itemid=998\&lang=ar.

النحو العربي .كتاب اللغة لتلامذة السنة السابعة من التعليم الأساسي 21 [21]

[22] I. A. Al-Sughaiyer, and I. A. Al-Kharashi, "Arabic Morphological Analysis Techniques: A Comprehensive Survey," Journal of the
American Society for Information Science and Technology 55(3):189213. 2004.

[23] LDC, Linguistic Data Consortium. Buckwalter Morphological Analyzer Version 1.0, LDC2002L49, 2002. http://www.ldc.upenn.edu/Catalog/.

[24] N. Kermani, and D. S. Boumiza, "Pré analyse du Mot Arabe Basée sur une Approche de Filtrage pour une Analyse Morphologique," GEI06, Hammamet, 2006.

[25] A. Abdelkader, D. S. Boumiza, and R. Braham, "A categorization algorithm for the Arabic language," International Conference on Communication, Computer and Power (ICCCP'09), Muscat, February 2009

[26] F. Popwich, and C. Vogel, Chart parsing head-driven phrase structure grammar. Technical Report CSS-IS TR 90-01, Simon Fraser University, 1990 